\title{
Review
}

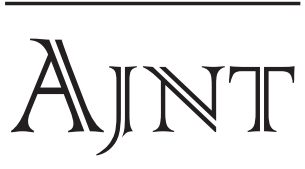

\section{Paraphenylene Diamine (Hair Dye) Poisoning in Children}

\author{
Mohamed Abdelraheem $^{\mathrm{a}^{*}}$, Mohamed Hamdouk ${ }^{\mathrm{b}}$, Eduard E Zijlstra ${ }^{\mathrm{c}}$ \\ a. Pediatric Nephrology Unit, Soba University Hospital, University of Khartoum, Sudan \\ b. Alsalam Dialysis Center, Khartoum, Sudan \\ c. Department of Medicine, Erasmus Medical Center, Rotterdam, The Netherlands
}

\begin{abstract}
Introduction: Paraphenylene Diamine (PPD) is an aromatic amine not found in nature. It is used in a variety of industrial products and in different hair dye formulations. It is well known that PPD is an allergen that may cause contact dermatitis, erythematous urticarial papules and eczema in susceptible individuals. However, the major systemic problem occurs when it is ingested accidentally, for purposes of suicidal intent or during attempted murder. Information on the systemic effects and outcome of hair dye poisoning in children is limited. In this article we review the literature for PPD intoxication in children.
\end{abstract}

Review: PPD intoxication is a major health problem in eastern Africa, particularly Sudan, and in Morocco. It is also common in the Indian subcontinent. In two large series from Morocco and Sudan, Children constituted $11.5 \%$ and $18 \%$ of affected individuals respectively. Acute poisoning by PPD causes characteristic severe angio-edema of the upper airway, often requiring tracheostomy, accompanied by a swollen, dry, hard and protruding tongue. PPD intoxication results in multisystem involvement and can cause rhabdomyolysis and acute kidney injury (AKI), flaccid paralysis, severe gastro-intestinal manifestations, cardiotoxicity and arrhythmias. This form of severe intoxication is fatal if not treated aggressively. There is no specific antidote and treatment is mainly supportive with renal replacement therapy commonly used in cases with AKI. Reported mortality rates range between $12-42 \%$.

Conclusion: PPD intoxication is a life threatening condition. Clinical outcomes rely on early recognition, prompt referral, and aggressive supportive treatment in collaboration with different specialties.

\footnotetext{
* Corresponding author; Soba University Hospital, Department of Paediatrics and Child Health, Khartoum, Sudan.

E mail: elfakky@hotmail.com
}

Keywords: Children; Hair Dye; Paraphenylene Diamine; Poisoning

\section{The authors declared no conflict of interest}

\section{Introduction}

Paraphenylene diamine (PPD) [C6H4 (NH2)2] is an aromatic amine not found in nature and it is produced commercially by many industrial companies (Figure 1). It is a derivative of paranitroanaline that is available in the form of white crystals when pure and rapidly turns to brown when exposed to air [1]. It is widely used in industrial products such as textile or fur dyes, dark colored cosmetics, temporary tattoos, photographic development and lithography plates, photocopying and printing inks, black rubber, oils, greases and gasoline [2].

PPD is the most common constituent of hair dye formulations. It is often the key ingredient but can also be used for color enhancement. PPD is commonly used in its raw form for cosmetic purposes in Africa, Middle East and Indian subcontinent while it is rarely used in the west $[1,3]$.

In Sudan, PPD is mixed with henna, leaves of Lawsonia Alba, which is a non toxic herb used to decorate the hands and feet in special social events, such as wedding ceremonies [3]. Henna needs to be applied to the skin several times in order to achieve the deep brown or black color. When PPD is added to henna, it reduces the number of skin application to one. More often, PPD is used separately.

In Morocco, a non-toxic herbal extract from the gallnut of athel-pine (Tamarix aphyla) is traditionally used to dye hair. This natural extract is locally known as "takawt". Its rarity resulted in the use of PPD as a substitute under the misleading name of "occidental takawt". Similarly in India, popular hair dyes (e.g. Super Vasmol $33^{\mathrm{TM}}$ ) contain PPD, among other ingredients $[4,5]$. 
Figure 1: Paraphenylene diamine (PPD) crystals

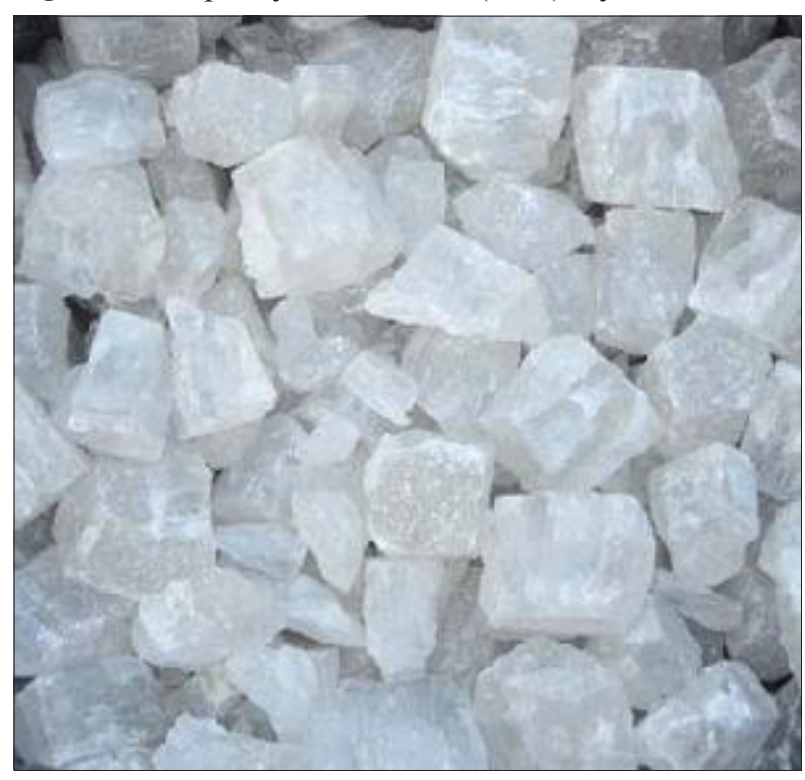

\section{Safety profile of PPD}

PPD is a well-known skin irritant and may be absorbed from the skin. Its systemic effects include angio-edema in particular in the face and neck, renal and cardiac toxicity, and rhabdomyolysis; it is also mutagenic and carcinogenic. The concentration of PPD in different hair dyes range from $0.2 \%$ to $3.75 \%$. The exact concentration that causes toxicity is not known [6]. Interestingly, variable concentrations of PPD are used in different hair dye formulations from different countries depending on the local manufacturer advice. All such recommendations are related to formulations used to dye hair and safe concentrations regarding skin application and decoration are not known. In countries where PPD is produced (Germany, Japan and UK) it is considered an occupational health hazard and the standard for air contamination developed by health authorities is $0.1 \mathrm{mg} / \mathrm{m}^{3}$ in the working atmosphere [6].

It is worth mentioning that the amount of PPD that can cause systemic poisoning is only three grams, while the lethal dose is 7-10 grams. In many countries in the Middle East PPD is freely available at low cost on local markets; $10 \mathrm{~g}$ of PPD can be bought for less than one US Dollar.

\section{Epidemiology}

PPD poisoning is a common health problem in the Middle East, especially Sudan and Morocco. It is also common in India but rare in the west. Most reported cases were from adolescents and adults, but a significant number of cases occur among children [3, 4, 7-9].
In Sudan, over a 10-year period (1995-2005), 3159 patients were reported to suffer from PPD poisoning; among these were $568(18 \%)$ children below the age of 14 years. In a study from Morocco, $11.5 \%$ of affected patients were children less than 15 years of age $[4,9]$.

Children are particularly vulnerable to toxicity of the dye because of their close contact with family members using PPD and the custom of decorating their hands in special occasions. In an early report from Sudan, 31 children with PPD intoxication were described over a 5-year period with a mean age of 9.5 years. Accidental ingestion was reported in 12/31 (38.7\%) while deliberate self harm was seen in 10/31 (32\%) children. In six children (19\%), toxicity through accidental skin absorption was suggested. In $9.6 \%$ the intoxication was thought to have occurred as a homicidal act. The striking feature of this study was the high mortality rate of $42 \%$; all deaths occurred within 24 hours of diagnosis [3].

A more recent report, also from Sudan, described PPD poisoning in 17 children with a mean age of 13.8 years. It showed that deliberate self harm was the commonest mode of poisoning, affecting 13/17 (76.4\%) children. Poisoning was intentional in three $(17.6 \%)$ children and accidental in one child. In contrast to the previous report the mortality rate was lower $(12 \%)$, possibly because of the availability of dialysis facilities, early referral and collaboration with ENT departments [10]. The increased public awareness of PPD toxicity may have resulted in the increased number of suicidal intents; especially with the unrestricted availability of PPD. Legislations to prevent PPD trade and use in the local market in Sudan were only recently approved by the local authorities, in 2008 .

A study from Morocco described 374 cases of PPD poisoning in adults and children over a 10 -year period. The majority of patients (54\%) were in the 15-24 years age group and children contributed significantly to the study population $(11.5 \%)$. The majority of poisoning was intentional $(78.1 \%)$. However, children were not analyzed separately for the cause of poisoning [4].

A report from Tunisia showed similar results [11], and a report from Saudi Arabia documented a suicide attempt with PPD in a 14-year old female [12].

\section{Clinical manifestations}

PPD intoxication is a life threatening condition. Clinical outcomes rely on early recognition, prompt referral, and aggressive supportive treatment in collaboration with different specialties. The toxicity of PPD is a multisystem involvement. The initial presentation may be confusing and most deaths occur within hours of admission. A typical case is illustrated by the following account: 
A six-year old child presented with sore throat, cough and anorexia followed by severe dyspnoea caused by edema of the tongue, pharynx and neck. He developed AKI and metabolic acidosis. The initial diagnosis was Ludwig's angina. Despite initiation of vigorous supportive therapy, the child developed irreversible ventricular fibrillation and died eight hours after admission. It was discovered later that the child and his dog ingested a hair dye containing PPD, and the dog died few hours later [13]. Another victim of PPD intoxication died of cardiac complications, which occurred 4 hours after admission despite intensive supportive measures [2]. Clinical scenarios are variable and range from a local skin reaction to multisystem involvement affecting the central nervous system and the musculoskeletal system. It is very important to obtain a psychosocial history and evaluate the home environment as many cases were found to be precipitated by severe psychiatric disturbances.

\section{Skin and eye manifestations}

The toxicity of PPD was first described in a hair dresser in 1924 following exposure due to occupational handling [14]. Nowadays, it is well known that PPD cause skin irritation, kerato-conjunctivitis, conjunctival swelling and eczema of the eyelids. Allergic reactions causing dermatitis, urticaria and asthma have also been reported $[15,16]$.

\section{Respiratory system and upper airway manifestations}

One of the most severe clinical manifestations and the main cause of death in PPD poisoning is upper airway obstruction (angio-edema) manifesting with a hard swollen protruding tongue and edematous bull neck. This has been reported in almost all affected children (31) in one study, $50 \%$ of such children required emergency tracheostomy [3]. In another report, $47 \%$ of affected children required tracheostomy for upper airway obstruction similar to reports from adult literature [10].

\section{Kidney manifestations}

The cardinal features of myoglobinuria (dark-colored, chocolate-brown urine), angio-edema and the sudden onset of symptoms and signs are used for the diagnosis of PPD poisoning in many places where there is lack of laboratory facilities. The extent of renal involvement varies between transient proteinuria and oliguric AKI. AKI commonly develops a few days after PPD exposure. The kidney injury is thought to be due to the direct toxic effect of PPD, hypovolumia, hemolysis and rhabdomyolysis with the deposition of myoglobin casts within the renal tubules $[11,17,18]$. In a study of 19 patients who underwent renal biopsy, glomerular injury was the most common (94\%) finding, followed by interstitial lesions (84\%) and tubular lesions (79\%). No evidence of vascular injury was found [18]. AKI may be severe enough to require dialysis; in two reports on children 5/31 (16\%) and 9/17 (53\%) respectively needed dialysis following PPD intoxication $[3,10]$.

\section{Neuromuscular toxicity}

The toxic effect of PPD on muscles results in rhabdomyolysis, which in turn contributes to AKI and the increased likelihood of sudden cardiac death [11]. This was demonstrated in animal studies where skeletal and cardiac muscle necrosis could be experimentally induced by PPD [19]. Scattered coagulative necrosis of skeletal muscles was found in the autopsy of a PPD victim [2]. Increased free radical formation in PPD poisoning may be responsible for the deleterious tissue damage observed in animal studies [20]. Flaccid paraplegia, palatopharyngeal and laryngeal paralysis were also reported in adults and children [21]. Neurotoxicity causing mental alteration and coma was also observed and was possibly related to brain anoxia and severe metabolic acidosis associated with AKI [8].

\section{Other manifestations}

Tender palpable liver with features of acute hepatitis on liver biopsy was seen in many patients [18]. Cardiac toxicity causing arrhythmia, heart block and sudden death was also reported in some studies. It is commonly the direct cause of death in children and adults with PPD poisoning. Cardiac toxicity is mainly caused by the direct toxic effect of PPD on the heart, rhabdomyolsis of the cardiac muscle causing severe damage and hyperkalemia $[10,22,23]$.

\section{Diagnosis}

The diagnosis of PPD intoxication is largely dependent on clinical manifestations. The clinical features are rather unique and in the absence of laboratory facilities in many developing countries the angio-edema of the face and neck together with the hard protruding tongue and the chocolate-brown color of the urine are used for clinical diagnosis [21]. Organ damage may be assessed by appropriate tests for rhabdomyolysis, and kidney and liver involvement. The urine can be tested for PPD using thin layer chromatography which is essential for medico-legal purposes [8]. However, this test is not routinely available and there is a need for a rapid test to demonstrate PPD in blood or urine.

\section{Management}

Treatment is mainly supportive depending on clinical features at presentation. Tracheostomy is a life saving measure for an obstructed airway, and some patients may need endotracheal intubation [9]. Antihistamines and 
steroids are commonly used because of the possibility of a hypersensitivity reaction to PPD but there is no evidence to support this mode of treatment. Alkaline diuresis using isotonic saline, sodium bicarbonate and diuretics is used in the management of myoglobinuria with variable results [11]. There is no specific antidote available, and trials of PPD removal using hemoperfusion and hemodialyis had variable results. However, dialysis is an effective supportive measure in case of oliguric or anuric AKI [18].

\section{Conclusion}

PPD intoxication is a life threatening condition. Clinical outcomes rely on early recognition, prompt referral, and aggressive supportive treatment in collaboration with different specialties. Health authorities should call for the prevention of the use and trade of PPD in the market. Awareness programs about its toxicity should be implemented at different levels.

\section{Reference}

1. Chugh KS, Malik GH, Singhal PC. Acute renal failure following paraphenylene diamine [Hair dye] poisoning: report of two cases. J Med. 1982;13(1-2):131-7.

2. Ashraf W, Dawling S, Farrow LJ. Systemic paraphenylene diamine (PPD) poisoning: a case report and review. Hum Exp Toxicol. 1994 Mar;13(3):167-70.

3. Sir Hashim M, Hamza YO, Yahia B, Khogali FM, Sulieman GI. Poisoning from henna dye and paraphenylenediamine mixtures in children in Kartoum. Ann Trop Paediatr. 1992;12(1):3-6.

4. Filali A, Semlali I, Ottaviano V, Fumari C, Corradini D, Soulaymani R. A retrospective study of acute systemic poisoning of paraphenylenediamine (occidental takawt) in Morocco. Afr J Trad. 2006;3(1):142-9.

5. Anuradha S, Arora S, Mehrotra S, Arora A, Kar P. Acute renal failure following paraphenylenediamine (PPD) poisoning; A case report and review. Ren Fail. 2004 May;26(3):329-32.

6. [No authors listed]. Overall evaluations of carcinogenicity: an updating of IARC Monographs volumes 1 to 42. IARC Monogr Eval Carcinog Risks Hum Suppl. 1987;7:1-440.

7. El Ansary EH, Ahmed ME, Clague HW. Systemic toxicity of paraphenylenediamine. Lancet. 1983 Jun 11;1(8337):1341.

8. Yagi HI, el Hind AM, Khalil SI. Acute poisoning from hair dye. East Afr Med J. 1991 Jun;68(6):404-11.
10. Abderlraheem MB, El-Tigani MA, Hassan EG, Ali MA, Mohamed IA, Nazik AE. Acute renal failure owing to paraphenylene diamine hair dye poisoning in Sudanese children. Ann Trop Paediatr. 2009 Sep;29(3):191-6.

9. Hamdouk MI, Abdelraheem MB, Taha AA, Benghanem M, De Broe ME. Paraphenylene diamine hair dye poisoning. In: De Broe ME, Porter GA, Bennett WM, Deray $G$, editors. Clinical nephrotoxins: renal injury from drugs and chemicals. 3rd ed. NewYork: Springer; 2008. p. 671-9.

11. Kallel H, Chelly H, Dammak H, Bahloul M, Ksibi H, Hamida CB, Chaari A, Rekik N, De Broe ME, Bouaziz M. Clinical manifestations of systemic paraphenylene diamine intoxication. J Nephrol. 2005 May-Jun;18(3):308-11.

12. Ashar A. Acute angioedema in paraphenylene diamine poisoning. J Pak Med Assoc. 2003 Mar;53(3):120-2.

13. Lifshits M, Yagoubsky P, Sofer S. Fatal paraphenylenediamine (hair dye) intoxication in a child resembling Ludwig's angina. J Toxicol Clin Toxicol. 1993;31(4):653-6.

14. Nott HW. Systemic poisoning by hair dye. Br Med J. 1924 Mar;1(3297):421-2.

15. Seidnari S, Di Nardo A, Motolese A, Pincelli C. [Erythema multiforme associated with contact sensitization. Description of 6 clinical cases]. G Ital Dermatol Venereol. 1990 Feb;125(1-2):35-40. [Article in Italian]

16. Nethercott JR, MacPherson M, Choi BC, Nixon P. Contact dermatitis in hairdressers. Contact Dermatitis 1986 Feb;14(2):73-9.

17. Suliman SM, Homeida M, Aboud OI. Paraphenylenediamine induced acute tubular necrosis following hair dye ingestion. Hum Toxicol. 1983 Oct;2(4):633-5.

18. Hamdouk M. Paraphenylene diamine (Hair Dye) Acute Systemic toxicity [Master's Thesis]. [Sheffield] Sheffield Kidney Institute; 2001. PPD nephrotoxicity; p. 34-47.

19. Munday R, Manns E, Fowke EA, Hoggard GK. Muscle necrosis by N-Mthylated paraphenylenediamine in rats: structure-activity relationship and correlation with free radical production in vitro. Toxicology. 1989 Aug;57(3):303-14. 
20. Muthur AK, Gupta BN, Narang S, Singh S, Mathur N, Singh A, Shakula LJ, Ravi Shanker R. Biochemical and histopathological changes following dermal exposure to paraphenylene diamine in ginea pigs. J Appl Toxicol. 1990 Oct;10(5):383-6.

21. Mustafa OM. Acute poisoning with hair dye containing paraphenylene diamine: the Gazira experience. Journal of the Arab Board of Specialization. 2001:3(2).
22. Lifshits M, Yagupsky P, Sofer S. Fatal paraphenylenediamine (hair dye) intoxication in child resembling Ludwig's angina. J Toxicol Clin Toxicol. 1993;31(4):653-6.

23. Ababou A, Ababou K, Mosadik A, Lazreq C, Sbihi A. [Myocardial rhabdomyolysis following paraphenylene diamine poisoning]. Ann Fr Anesth Reanim. 2000 Feb;19(2):105-7. [Article in French] 